\title{
Basic Fibroblast Growth Factor and Brain-Derived Neurotrophic Factor Promote Survival and Neuronal Circuit Formation in Organotypic Hippocampal Culture
}

\author{
Yasuhiro Nakagami", Hiroshi Saito and Norio Matsuki* \\ Laboratory of Chemical Pharmacology, Graduate School of Pharmaceutical Sciences, The University of Tokyo, Tokyo 113, Japan
}

Received July 14, 1997 Accepted August 19, 1997

\begin{abstract}
Neurotrophic effects in vitro have been generally related to promotion of differentiation, maturation and survival, but little is known about the effect on neuronal circuit formation. The organotypic culture system would be an available technique to investigate neuronal circuit formation and neuronal cell-cell interactions. As we reported previously, an optical recording system is a useful technique to comprehend neuronal activities and circuit from multi-points simultaneously. In this study, we investigated whether continuous application of basic fibroblast growth factor (bFGF or FGF-2) and brain-derived neurotrophic factor (BDNF) inhibited neuronal cell death induced by serum-deprivation in organotypic culture using propidium iodide staining, and we analyzed effects of $\mathrm{bFGF}$ and BDNF on the formation of neuronal circuits using the optical recording system. Continuous application of bFGF or BDNF significantly protected the slices from neuronal death. Optical recording also demonstrated that addition of $10 \mathrm{ng} / \mathrm{ml} \mathrm{bFGF}$ or $50 \mathrm{ng} / \mathrm{ml}$ BDNF enhanced optical signals in all hippocampal areas significantly. These data strongly suggest that bFGF and BDNF promote the formation of neuronal circuits as well as survival and that optical recording of organotypic hippocampal slices would be a useful technique that enables us to analyze neuronal circuit formation easily.
\end{abstract}

Keywords: Basic fibroblast growth factor, Brain-derived neurotrophic factor, Hippocampus, Organotypic culture, Optical recording

Several neurotrophic factors regulate survival, differentiation and maintenance of neurons in developmental phases. Basic fibroblast growth factor (bFGF), a singlechain polypeptide composed of 146 amino acids, is wellknown to stimulate the proliferation and support the survival of neurons of various brain regions $(1-5)$. Specific localization of $\mathrm{bFGF}$ and its receptors during the development of the rat nervous system has been reported $(6,7)$. Brain-derived neurotrophic factor (BDNF) is a member of the neurotrophic gene family that is thought to play a critical role in the survival and differentiation of neurons $(4,5,8)$. BDNF is widely expressed in the central nervous system, with the highest levels of mRNA being found in the hippocampus (9). Although these reports demonstrate that $\mathrm{bFGF}$ and BDNF promote differentiation, maturation and survival, they do not evaluate the neurotrophic

\footnotetext{
" Research Fellow of the Japan Society for the Promotion of Science.

*To whom correspondence should be addressed.
}

effect from the point of view of neuronal circuit formation. One of the difficulties encountered in pursuing the neurotrophic effect in dissociated cells is that when the neurons are dissociated to single cells, the normal cell-tocell contact, which enables cells to affect each other, is not present. To overcome this problem, the organotypic culture system technique can be used to investigate neuronal circuit formation and neuronal cell-cell interactions, in contrast to dissociated neurons. Furthermore, the system retains neuronal morphology and architecture and displays characteristics such as developmental features and regional vulnerability manifested in vivo $(10-12)$.

Optical recording with voltage-sensitive dyes has been recognized as a good strategy to analyze synaptic connections, neuronal circuit and spatial-temporal pattern of neuronal activity $(13-15)$. The real-time recording system that we employed is feasible for recording $128 \times 128$ points with high time resolution of $0.6 \mathrm{msec}(16)$, and the system enabled us to investigate electrical activity in the 
hippocampus (17-19). We also reported an entorhinohippocampal system using an organotypic culture system by optical recording (20).

In this study, we investigated whether continuous application of bFGF and BDNF inhibited neuronal cell death that was induced by serum-deprivation in organotypic culture using propidium iodide (PI) staining. PI staining is well-known to be a good marker for cell degeneration because the dye can only enter cells with damaged membranes $(10,21-23)$. Next, we applied the optical image recording system to organotypic hippocampal slices to investigate the possibility that the analysis of neuronal circuit by optical recording could be a new strategy for testing the neurotrophic effects from the point of view of neuronal circuit formation.

\section{MATERIALS AND METHODS}

\section{Organotypic culture}

Organotypic cultures of the hippocampus were processed according to the interface method (24). Brains were rapidly removed from 8-day-old Wistar rats, and $300-\mu$ m-thick horizontal entorhino-hippocampal slices were cut using a microslicer. Slices were maintained in cold Gey's balanced salt solution supplemented with $6.5 \mathrm{mg} / \mathrm{ml}$ glucose bubbled with $95 \% \mathrm{O}_{2}$ and $5 \% \mathrm{CO}_{2}$. Medial entorhino-hippocampal slices with the entorhinal cortex were placed on a transparent membrane (Millicell$\mathrm{CM}$; Millipore, Bedford, MA, USA) with $1.0 \mathrm{ml}$ culture medium consisting of 50\% MEM (Gibco, Grand Island, NY, USA), 25\% Hank's balanced salt solution (HBSS) and $25 \%$ donor horse serum supplemented with 6.5 $\mathrm{mg} / \mathrm{ml}$ glucose, $50 \mathrm{U} / \mathrm{ml}$ penicillin $\mathrm{G}$ potassium and 100 $\mu \mathrm{g} / \mathrm{ml}$ streptomycin sulfate. For serum-free culture, 100 $\mu \mathrm{g} / \mathrm{ml}$ human transferrin, $5 \mu \mathrm{g} / \mathrm{ml}$ bovine insulin and 20 nM progesterone were added to the serum-free medium consisting of a $1: 1 \mathrm{mix}$ of HBSS and MEM. After 3.5 days in vitro, the medium was changed to the serum containing or serum-free medium. bFGF and BDNF were also added into the medium after 3.5 days in vitro and they remained present continuously. The cultures were grown at $37.0^{\circ} \mathrm{C}$ in a moist $5 \% \mathrm{CO}_{2}$ atmosphere, and the culture medium was changed every 3.5 days.

\section{Optical recording}

Optical recording was performed according to the methods described previously with some modifications $(19,20)$. The preparation cultured for $10-14$ days was employed for optical recording. The cultures dissected with the transparent membrane were stained for $10 \mathrm{~min}$ in $0.2 \mathrm{mg} / \mathrm{ml} \mathrm{RH155}$ (available as NK-3041 from Nippon Kankoh-Shikiso Kenkyusho, Okayama) $(19,20,25-27)$ solution dissolved in artificial cerebrospinal fluid (ACSF) having the following composition: $127 \mathrm{mM} \mathrm{NaCl}, 1.6$ $\mathrm{mM} \mathrm{KCl}, 1.24 \mathrm{mM} \mathrm{KH} \mathrm{PO}_{4}, 1.3 \mathrm{mM} \mathrm{MgSO}, 2.4 \mathrm{mM}$ $\mathrm{CaCl}_{2}, 26 \mathrm{mM} \mathrm{NaHCO}$ and $10 \mathrm{mM}$ glucose, which was continuously bubbled with a mixture of $95 \% \mathrm{O}_{2}$ and $5 \%$ $\mathrm{CO}_{2}$, and then washed in ACSF for at least $15 \mathrm{~min}$. The conventional electrophysiological technique of extracellular recordings was employed to check the maximal responses of the synaptic formation and to adjust the stimulus strength. A glass electrode filled with $0.9 \% \mathrm{NaCl}$ and a pair of stimulating electrodes were placed on the pyramidal layer of $\mathrm{CA} 3$ and the mossy fiber, respectively. A rectangular pulse $(0.5-1.0 \mathrm{~mA})$ of $100 \mu \mathrm{sec}$ duration was delivered every $15 \mathrm{sec}$ with a strength that gave the maximum amplitude of field population spikes.

The optical recording system (HR Deltaron 1700; Fuji Photo Film, Tokyo) consisted of a $128 \times 128$ photodiode array and a processing unit (16). Transmitted light with a wavelength of $700 \pm 20 \mathrm{~nm}$ was projected. The duration of light exposure was shortened to 1 sec by a mechanical shutter to avoid photodynamic damage and dye bleaching. Before stimulation, a 128 frames averaged image of background light signal was stored in a reference memory. The stored reference data were continuously subtracted from real-time images and transferred to the unit sequentially at a frame rate of $0.6 \mathrm{msec}$. One trial consisted of 512 real-time images, and 16 trial images were averaged to improve the signal-to-noise ratio.

\section{PI fluorescence}

After 14 days in vitro, the cultures were transferred to the medium containing $10 \mu \mathrm{g} / \mathrm{ml}$ PI. Twenty-four hours later, PI fluorescence imaging was carried out with a laser scanning confocal system MRC-600 (BioRad, Hercules, CA, USA) equipped with an inverted microscope (Nikon, Tokyo), an argon ion laser and a host computer system. All image generation and processing operations were performed by software provided with the confocal system. For the measurements of PI intensity, the tissue was illuminated with the excitation wavelength of $514 \mathrm{~nm}$, and fluorescence images were obtained through a 550-nm band-pass filter. The tissue was viewed with a $4 \times$ objective using a phase-contrast condenser to obtain fluorescence images. To quantify the intensity of PI fluorescence on the tissue, the pixel intensity values $(0-255)$ of 10 trials obtained by the maximum pixel mode were averaged for each hippocampal subfield. Computer analysis of each image was performed by creating 3 pixels $(82.5-\mu \mathrm{m}$ square) around each pyramidal and granule cell layer (10, 22). Results were expressed as a percentage of the value obtained from dentate gyrus (DG) in the serum-free medium and as means \pm S.E.M. Statistical analysis of the values was performed by Dunnett's multiple range test. 


\section{Reagents}

The bFGF used in the present study is an acid-resistant mutein of human bFGF, CS23 (a generous gift from Takeda Chemical Industries, Ltd., Osaka). The activity of CS23 on brain neurons is virtually the same as those of wild type of human bFGF and bovine bFGF (28). bFGF and human recombinant BDNF (a generous gift from Sumitomo Pharmaceutical Co., Osaka) was dissolved in phosphate-buffered saline containing $0.1 \%$ bovine serum albumin and stored at $-30^{\circ} \mathrm{C}$.

\section{RESULTS}

PI fluorescence was quite intense in control tissues cultured in the serum-free medium after 3.5 days in vitro (Fig. 1A). As expected, the culture that remained in serum-containing medium did not show significant cell death in all hippocampal areas (Fig. 1B). Compared to the serum-free control, the continuous presence of $b F G F$ and BDNF apparently reduced PI fluorescence in the hippocampal organotypic culture (Fig. 1: C and D), suggesting that addition of bFGF and BDNF could protect neuronal cells from cell death induced by serum-deprivation medium in organotypic culture. Table 1 summarizes the PI fluorescence imaging data. Preferential loss of pyramidal neurons was observed in the CAl region and the entorhinal cortex following serum-deprivation. Addition of bFGF or BDNF $(1-100 \mathrm{ng} / \mathrm{ml})$ to the serum-free medium and its continuous presence induced a concentration-dependent decrease of neuronal damage. PI fluorescence of each area was not significantly reduced by $1 \mathrm{ng} / \mathrm{ml} \mathrm{bFGF}$ or BDNF compared to the serum-free control. However, increasing the concentration of bFGF to $100 \mathrm{ng} / \mathrm{ml}$ reduced PI fluorescence by $20-70 \%$, and $100 \mathrm{ng} / \mathrm{ml}$
BDNF reduced the neuronal damage by $40-70 \%$. Although DG and the CA3 region, which exhibited less damage than $\mathrm{CAl}$, were somewhat protected at the highest concentration of $100 \mathrm{ng} / \mathrm{ml} \mathrm{bFGF}$ that was necessary for the significant reduce of the damage within CA1 and the entorhinal cortex, the reduction of fluorescence did not reach statistical significance. In contrast, 100 $\mathrm{ng} / \mathrm{ml} \mathrm{BDNF}$ significantly protected all the hippocampal areas from the neuronal damage. The neuroprotection in DG obviously decreased at $100 \mathrm{ng} / \mathrm{ml}$ BDNF.

In order to confirm that not only neuronal survival but also the formation of connections between neurons was
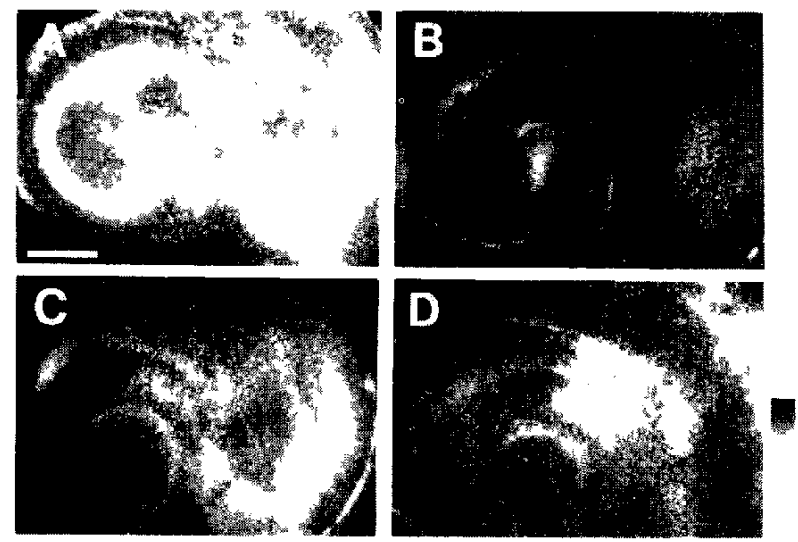

Fig. 1. PI fluorescence images of organotypic entorhino-hippocampal cultures. A: Serum-free control. Note that neuronal damage is limited to the neuronal cell layers of the organotypic culture. B: Serum containing control. Virtually, no PI labeling cells were observed. C: Addition of $10 \mathrm{ng} / \mathrm{ml} \mathrm{bFGF}$. D: Addition of 50 $\mathrm{ng} / \mathrm{ml} \mathrm{BDNF}$. The presence of bFGF or BDNF induced neuroprotection, especially in CA1 and the entorhinal cortex. Scale bar in panel $\mathrm{A}$ is $500 \mu \mathrm{m}$ and applicable to all panels.

Table 1. Neuroprotective effect of bFGF and BDNF against serum deprivation

\begin{tabular}{|c|c|c|c|c|}
\hline & DG & $\mathrm{CA} 3$ & CA1 & Ent \\
\hline Control HS (-) & $100.0 \pm 2.7$ & $61.2 \pm 3.7$ & $184.7 \pm 14.6$ & $137.2 \pm 8.8$ \\
\hline Control HS ( + ) & $15.0 \pm 5.9^{* * *}$ & $27.3 \pm 6.0^{* *}$ & $24.0 \pm 5.4^{* *}$ & $13.5 \pm 3.3^{* *}$ \\
\hline bFGF $1(\mathrm{ng} / \mathrm{ml})$ & $92.5 \pm 4.6$ & $57.1 \pm 4.5$ & $145.6 \pm 7.1$ & $117.2 \pm 10.9$ \\
\hline 10 & $81.3 \pm 5.8$ & $47.9 \pm 1.8$ & $123.3 \pm 8.4^{* *}$ & $90.0 \pm 10.4^{*}$ \\
\hline 100 & $80.1 \pm 4.6$ & $51.8 \pm 1.8$ & $112.0 \pm 3.7^{* *}$ & $47.3 \pm 5.7^{* *}$ \\
\hline BDNF $1(\mathrm{ng} / \mathrm{ml})$ & $74.1 \pm 13.4$ & $47.8 \pm 4.3$ & $173.1 \pm 19.9$ & $112.4 \pm 15.4$ \\
\hline 10 & $64.3 \pm 13.4^{*}$ & $42.7 \pm 3.8^{*}$ & $111.4 \pm 8.6^{* *}$ & $98.8 \pm 8.7$ \\
\hline 50 & $38.4 \pm 9.7^{* *}$ & $32.4 \pm 4.5^{* *}$ & $73.5 \pm 7.3^{* *}$ & $81.5 \pm 15.0^{* *}$ \\
\hline 100 & $60.4 \pm 8.8^{*}$ & $34.2 \pm 7.2^{* *}$ & $78.0 \pm 4.5^{* *}$ & $48.6 \pm 13.7^{* *}$ \\
\hline
\end{tabular}

Results are expressed as a percentage of the fluorescence intensity obtained from DG in the serum-free control and as means \pm S.E.M., $\mathrm{n}=6$ to $7 .{ }^{*} \mathrm{P}<0.05,{ }^{* *} \mathrm{P}<0.01$ vs each Control HS ( - ) (Dunnett's multiple range test). Ent: entorhinal cortex, HS: horse serum. 

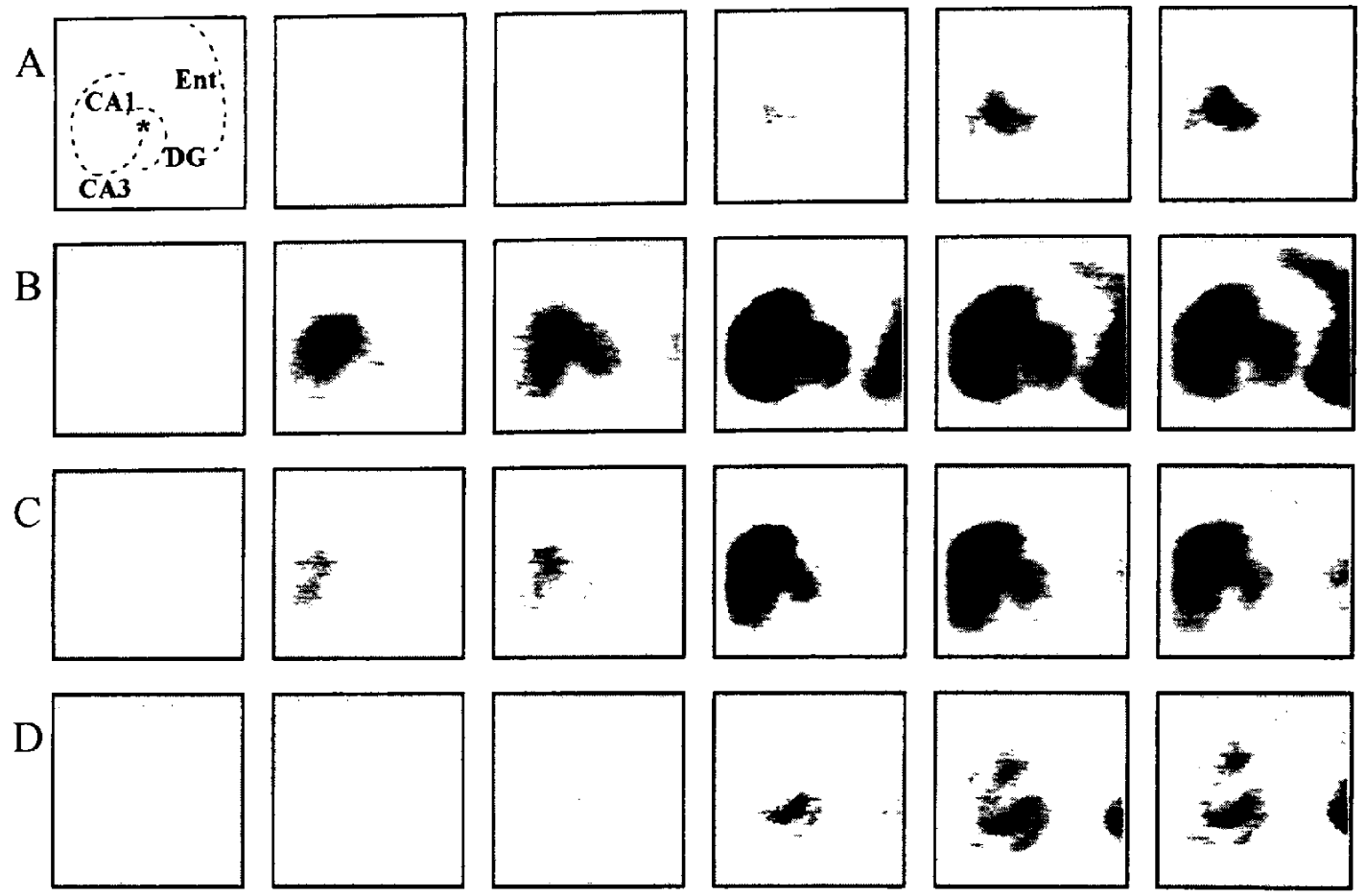

$0 \mathrm{msec}$

$6.0 \mathrm{msec}$

$12.0 \mathrm{msec}$

$18.0 \mathrm{msec}$

$24.0 \mathrm{msec}$

$30.0 \mathrm{msec}$
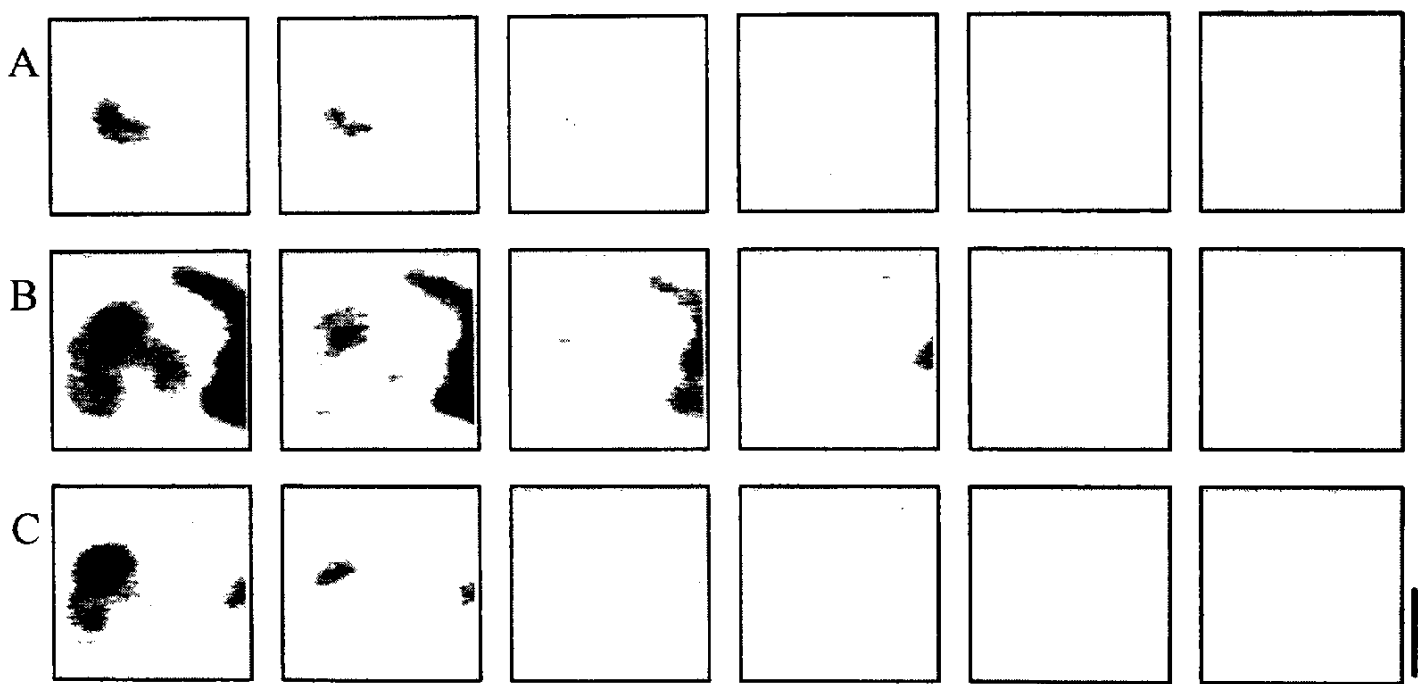

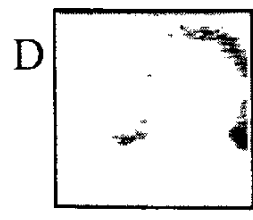

$360 \mathrm{msec}$

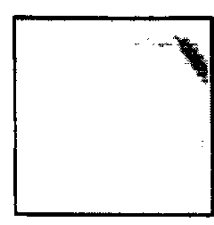

$42.0 \mathrm{msec}$

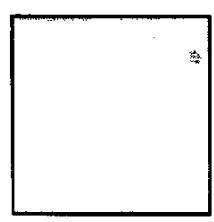

$48.0 \mathrm{msec}$

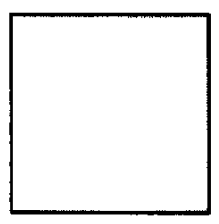

$54.0 \mathrm{msec}$

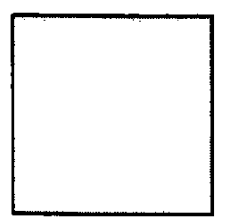

$600 \mathrm{msec}$
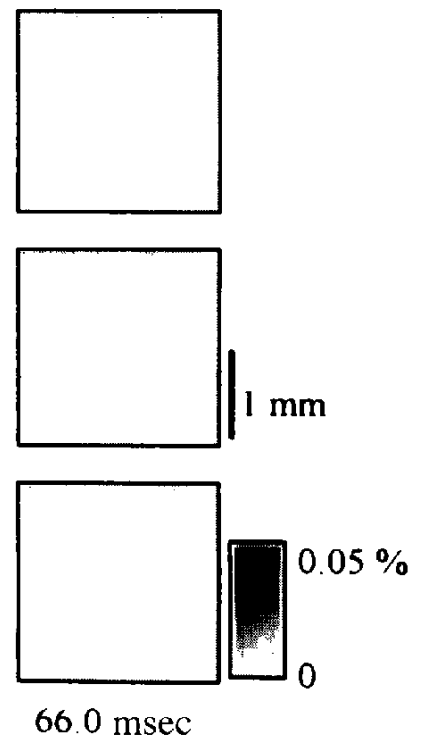

Fig. 2. Optical signal propagation in the entorhino-hippocampal organotypic culture. A: Serum-free control. Numerals under the images correspond to time after the stimulus delivery. The fractional absorbance change was monochrome-coded, as shown by the pseudo-monochrome scale in the bottom right corner. Dashed lines in the 0 -msec image indicate the approximate outline of pyramidal and granule cell layers of the hippocampus and the layer of the entorhinal cortex. An asterisk indicates the stimulus site. The excitatory propagation into the entorhinal cortex from the hippocampus was almost invisible. B: Serumcontaining control. C: Addition of $10 \mathrm{ng} / \mathrm{ml}$ bFGF. D: Addition of $50 \mathrm{ng} / \mathrm{ml}$ BDNF. The presence of bFGF or BDNF increased signal propagation compared to the serum-free control. 
accelerated by addition of bFGF and BDNF, we investigated the spatial-temporal propagation of neuronal activities in organotypic cultures using the real-time optical recording system. To test the neuroprotective effect of bFGF and BDNF on neuronal circuit formation, we used tissues cultured with $10 \mathrm{ng} / \mathrm{ml} \mathrm{bFGF}$ or $50 \mathrm{ng} / \mathrm{ml} \mathrm{BDNF}$ according to the PI imaging data results. We previously reported that stimulation of the perforant pathway induced serial excitation in the trisynaptic pathway of the hippocampus (19) and sequentially in layer $V$ from the medial to the lateral entorhinal cortex (20). Although the same propagation was also observed in slices cultured in serum-containing medium, the propagation was almost invisible in the slices cultured in serum-free, bFGF-containing or BDNF-containing medium after stimulation of the perforant pathway (data not shown). We therefore evaluated the neuronal circuit by stimulating the mossy fiber with maximum intensity. Before stimulation, no spontaneous optical response was detected. As shown in Fig. 2B, the neuronal activity first spread on $\mathrm{CA} 3$ and then propagated to $\mathrm{CA} 1$ and the entorhinal cortex, sequentially. The application of $10 \mu \mathrm{M} 6$-cyano-7-nitro-
(A)

control HS( - )

control HS(+)

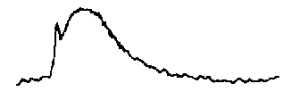

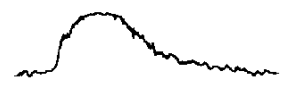

bFGF $10 \mathrm{ng} / \mathrm{ml}$
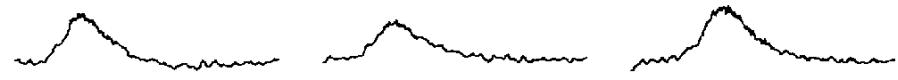

BDNF $50 \mathrm{ng} / \mathrm{ml}$
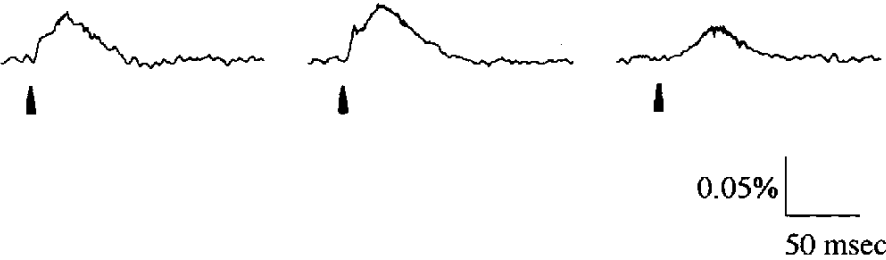

(B)

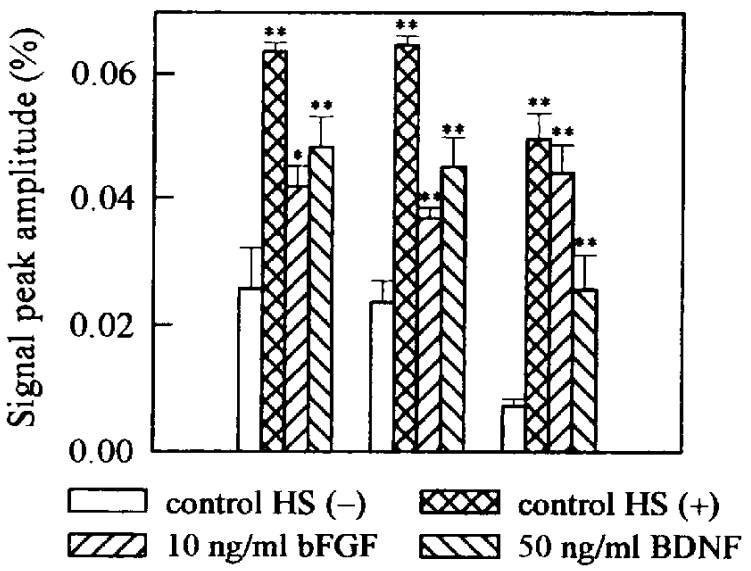

Fig. 3. Potentiation of optical signal amplitudes by addition of bFGF or BDNF. A: Typical time course of the optical signals after stimulation of the mossy fiber. The recording positions of the signals correspond to the 0 -msec image in Fig. 2. Stimulus delivery is indicated as arrowheads. B: Optical signals obtained after stimulation of the mossy fiber with maximum intensity. All data are expressed as means \pm S.E.M. ${ }^{*} \mathbf{P}<0.05,{ }^{* *} \mathbf{P}<0.01$ vs control HS $(-)$ by Dunnett's multiple test, $\mathbf{n}=6$ to 7 . HS: horse serum. 
quinoxaline (CNQX), a non- $N$-methyl-D-aspartate receptor antagonist, blocked the propagation of the optical signals, indicating that the optical responses were originated from the synaptic response, not just from action potentials of stimulated axons (data not shown). However, in the slice cultured in the serum-free medium, the excitatory propagation was weak and the invasion of the neuronal activities from the hippocampus to the entorhinal cortex was almost undetectable, suggesting that the projections from the CA1 region to the entorhinal cortex were more vulnerable than the ones from $\mathrm{CA} 3$ to CA1. The neurotrophic effects of bFGF and BDNF on forming a neuronal circuit are apparent in Fig. 2, C and $D$. The neuronal activities were enhanced by addition of bFGF or BDNF, and the invasion into the entorhinal cortex was again recorded clearly.

The time course of the optical signals in CA3, CA1 and the entorhinal cortex is shown in Fig. 3A, and all traces represent the average of 16 sweeps with an interval of 15 sec. The optical signal amplitudes in bFGF- and BDNFtreated cultures were increased compared to ones in the serum-free control. The optical signal in CA3 of the serum-containing control was definitely divided into fast and slow components (Fig. 3A) $(13,17)$. The fast and slow components would mainly reflect the action potentials in the stimulated axons and the excitatory monoand/or poly-synaptic potentials, respectively. In addition, the change of membrane potentials in interneurons and/or glial cells would also contribute to the generation of the optical signals. The distinction between the fast and slow components disappeared in CA1 or the entorhinal cortex away from the stimulus site, presumably because of decrease in synchronization of discharges. The distinction in CA3 of the serum-free control was also more subtle than that in the serum-containing control, suggesting that the neuronal circuit connection was too weak and immature to induce a synchronized action potential in the serum-free control. Figure 3B summarizes the optical signal amplitude. Both $\mathrm{bFGF}$ and BDNF enhanced optical signal amplitudes significantly in all hippocampal areas compared to the ones in the serum-free control.

\section{DISCUSSION}

PI labeling demonstrated that $\mathrm{bFGF}$ and $\mathrm{BDNF}$ $(1-100 \mathrm{ng} / \mathrm{ml})$ showed a neuroprotective effect against cell death induced by serum-deprivation in organotypic culture (Fig. 1, Table 1). The concentration of bFGF and BDNF required for neurotrophic effects in our system is similar to those reported to stimulate the proliferation and survival in dissociated cells $(2,3,5,8)$. It would be remarkable that concentration similarities concerning neurotrophic effects were observed in both dissociated cells and organotypic cultures (23). Interestingly, BDNF was also shown to attenuate the apoptotic death induced by serum-deprivation; however, pretreatment with BDNF markedly potentiated the necrotic death in cortical cell culture (8). Whether the neuronal death observed here in organotypic cultures is apoptotic or necrotic, the effect of pretreatment of BDNF and the involvement of TrkB, p75NTR or both should be investigated more precisely in the future. In addition, although the neuronal survival was confirmed to be potentiated relatively by addition of bFGF or BDNF using PI labeling after continuous serum-deprivation, PI fluorescence might not faithfully represent absolute neuronal death. Because PI binds to DNA and RNA, PI is unable to detect the neurons that died and resulted in denaturation of intracellular nucleic acids during serum-deprivation (29). Therefore, further studies would be certainly required to elucidate how far each hippocampal neuron was damaged in organotypic culture under our experimental conditions.

Stimulation of the mossy fiber induced serial excitatory propagation in CA3, CA1 and the entorhinal cortex (Fig. 2). The neuronal networks were the same as the ones manifested in vivo (30). Optical recording also demonstrated that bFGF and BDNF increased optical signals in all hippocampal areas, strongly suggesting that they enhanced formation of synapses and appropriate networks (Figs. 2 and 3). This enhancement of optical signals would mainly attribute to the survival of hippocampal neurons. However, their induction effect of neuronal differentiation might also contribute to the optical response because these factors are known to cause a marked increase in axon number and length of mossy fiber using dentate granule cell layer collagen explant cultures (31). Taken together, these results may provide evidence for the involvement of bFGF and BDNF in directing neurogenesis and forming neuronal circuits, and optical signal would be a good marker to quantify formation of the functional synapses.

In these experiments, we only used the organotypic slices cultured for 10-14 days. Synaptic development in the hippocampus is determined by a process that occurs in the first 3-4 weeks after birth $(32,33)$. Indeed, the time course of synaptic formation and the onset of long-term potentiation in organotypic hippocampal culture from 2to 8-day-old rats were examined in detail by measuring evoked field population spikes (12), which suggested that the responses reached a plateau level within 10-15 days. The organotypic hippocampal slices cultured for 10-15 days seem to be most suitable for investigating neuronal activity and plasticity. We changed the medium to the serum-free medium after 3.5 days in vitro. Therefore, neurotrophic actions observed here would result from the 
potentiation of survival and following circuit formation rather than the maintenance of neuronal network.

Continuous serum-deprivation degenerated the perforant pathway, but did not damage the mossy fiber and the Schaffer collaterals severely. The segment of the entorhinal cortex and the hippocampus contained in the individual transverse slices would be separated from each other because the entorhino-hippocampal fiber projections incline dorsally (30). As a result, the connections between the two segments are almost disconnected when making a transverse hippocampal slice (34). For these reasons, the perforant pathway was probably most vulnerable to serum-deprivation in entorhino-hippocampal organotypic cultures, and optical signals were almost invisible in slices cultured in serum-free medium after stimulation of the perforant pathway.

As stated in the introduction, neurotrophic effects in vitro are generally related to promotion of differentiation, maturation and survival in dissociated cells. The preservation of appropriate synaptic circuits and organotypic structure makes slice cultures a powerful in vitro model method for studying neuronal circuits. Our previous report (20) demonstrated that serial excitatory propagation in the entorhino-hippocampal system was observed in organotypic culture. In this study, we firstly presented that neuronal circuit formation was enhanced by addition of bFGF and BDNF using the optical recording technique. More detailed, many-sided information on the cellular level, especially histologic and immunocytochemical analysis, is certainly required to assert neuronal connections of anatomical circuits and clarify whether these neurotrophic effects are mediated by specific receptors or not. Nevertheless, we think that optical recording of organotypic hippocampal slices would be a useful and convenient technique that provides rapid analysis and quantification of neuronal circuit formation and contribute to finding new neurotrophic agents and their effects.

\section{REFERENCES}

1 Gospodarowicz D, Neufeld G and Schweiger L: Fibroblast growth factor. Mol Cell Endocrinol 46, 187-204 (1986)

2 Morrison RS, Sharma A, de Vellis J and Bradshow RA: Basic fibroblast growth factor supports the survival of cerebral cortical neurons in primary culture. Proc Natl Acad Sci USA 83, 7537- 7541 (1986)

3 Walicke P, Cowan WM, Ueno N, Baird A and Guilemin R: Fibroblast growth factor promotes survival of dissociated hippocampal neurons and enhances neurite extension. Proc Natl Acad Sci USA 83, 3012-3016 (1986)

4 Temple $S$ and Qian X: bFGF, neurotrophins, and the control of cortical neurogenesis. Neuron 15, 249-252 (1995)

5 Vicario-Abejón C, Jone KK, Hazel TG, Collazo C and McKay RDG: Functions of basic fibroblast growth factor and neurotrophins in the differentiation of hippocampal neurons. Neuron
$15,105-114(1995)$

6 Wanaka A, Milbrandt J and Johnson EM Jr: Expression of FGF receptor gene in rat development. Development 111, $455-468$ (1991)

7 Peters KG, Werner S, Chen G and Williams LT: Two FGF receptor genes are differentially expressed in epithelial and mesenchymal tissues during limb formation and organogenesis. Development 114, 233-243 (1992)

8 Koh JY, Gwag BJ, Lobner D and Choi DW: Potentiated necrosis of cultured cortical neurons by neurotrophins. Science 268, 573 - 575 (1995)

9 Hofer M, Pagliusi SR, Hohn A, Leibrock $J$ and Barde YA: Regional distribution of brain-derived neurotrophic factor mRNA in the adult mouse brain. EMBO J 9, 2459-2464 (1990)

10 Vornov JJ, Tasker RC and Coyle JT: Direct observation of the agonist-specific regional vulnerability to glutamate, NMDA, and kainate neurotoxicity in organotypic hippocampal cultures. Exp Neurol 114, 11-22 (1991)

11 Buchs PA, Stoppini L and Muller D: Structural modifications associated with synaptic development in area CA1 of rat hippocampal organotypic cultures. Dev Brain Res 71, 81-91 (1993)

12 Muller D, Buchs PA and Stoppini L: Time course of synaptic development in hippocampal organotypic cultures. Dev Brain Res 71, 93-100 (1993)

13 Grinvald A, Manker A and Segal M: Visualization of the spread of electrical activity in rat hippocampal slices by voltage-sensitive optical probes. J Physiol (Lond) 333, 269-291 (1982)

14 Bonheffer T, Staiger $V$ and Aertsen A: Synaptic plasticity in rat hippocampal slice cultures: Local "Hebbian" conjunction of pre- and postsynaptic stimulation leads to distributed synaptic enhancement. Proc Natl Acad Sci USA 86, 8113-8117 (1989)

15 Salzberg BM: Optical recording of voltage changes in nerve terminals and in fine neuronal processes. Annu Rev Physiol 51, 507-526 (1989)

16 Matsumoto $\mathrm{G}$ and Ichikawa $\mathrm{M}$ : Optical system for real-time imaging of electrical activity with a $128 \times 128$ photopixel array. Soc Neurosci Abstr 16, 490 (1990)

17 Barish ME, Ichikawa $M$, Tominaga $T$, Matsumoto $G$ and Iijima T: Enhanced fast synaptic transmission and a delayed depolarization induced by transient potassium current blockade in rat hippocampal slice as studied by optical recording. J Neurosci 16, 5672-5687 (1996)

18 Iijima T, Witter MP, Ichikawa M, Tominaga T, Kajiwara R and Matsumoto G: Entorhinal-hippocampal interactions revealed by real-time imaging. Science 272, 1176-1179 (1996)

19 Nakagami Y, Saito $H$ and Matsuki N: Optical recording of trisynaptic pathway in rat hippocampal slices with a voltagesensitive dye. Neuroscience 81, 1-8 (1997)

20 Nakagami $Y$, Saito $H$ and Matsuki N: Optical recording of rat entorhino-hippocampal system in organotypic culture. Neurosci Lett 216, 211-213 (1996)

21 Hsu SSF, Newell DW, Tucker A, Malouf AT and Winn HR: Adenosinergic modulation of CAl neuronal tolerance to glucose deprivation in organotypic cultures. Neurosci Lett 178, $189-192$ (1994)

22 Strasser U and Fisher G: Quantitative measurement of neuronal degeneration in organotypic hippocampal cultures after combined oxygen/glucose deprivation. J Neurosci Methods 57, $177-186(1995)$ 
23 Pringle AK, Sundstrom LE, Wilde GJC, Williams LR and lannotti F: Brain-derived neurotrophic factor, but not neurotrophin-3, prevents ischaemia-induced neuronal cell death in organotypic rat hippocampal slice cultures. Neurosci Lett 211, 203- 206 (1996)

24 Stoppini L, Buchs PA and Muller D: A simple method for organotypic cultures of nervous tissue. J Neurosci Methods 37, 173-182 (1991)

25 Konnerth A, Obaid AL and Salzberg BM: Optical recording of electrical activity from parallel fibres and other cell types in skate cerebellar slices in vitro. J Physiol (Lond) 393, 681-702 (1994)

26 Cinelli AR and Salzberg BM: Dendritic origin of late events in optical recordings from salamander olfactory bulb. J Neurophysiol 68, 786-806 (1992)

27 Vranesic I, Iijima T, Ichikawa $M$, Matsumoto $G$ and Knöpfel $\mathrm{T}$ : Signal transmission in the parallel fiber-Purkinje cell system visualized by high-resolution imaging. Proc Natl Acad Sci USA 91, 13014-13017 (1994)

28 Abe $K$, Takayanagi $M$ and Saito $H$ : Basic fibroblast growth factor and epidermal growth factor promote survival of primary cultured cerebellar neurons from neonatal rats. Jpn J Pharmacol 56, 113-116 (1991)
29 Sakagushi T, Okada M, Kuno M and Kawasaki K: Dual mode of $N$-methyl-D-aspartate-induced neuronal death in hippocampal slice cultures in relation to $N$-methyl-D-aspartate receptor properties. Neuroscience 76, 411-423 (1997)

30 Witter MP: Organization of the entorhinal-hippocampal system: A review of current anatomical data. Hippocampus 3, Suppl 33-44 (1993)

31 Lowenstein $\mathrm{DH}$ and Arsenault L: Dentate granule cell layer collagen explant cultures: Spontaneous axonal growth and induction by brain-derived neurotrophic factor or basic fibroblast growth factor. Neuroscience 74, $1197-1208$ (1996)

32 Pokorny $\mathbf{J}$ and Yamamoto $\mathrm{T}$ : Postnatal ontogenesis of hippocampal CAl area in rats. II. Development of ultrastructure in stratum lacunosum and moleculare. Brain Res Bull 7, 121-130 (1981)

33 Pokorny $\mathrm{J}$ and Yamamoto $\mathrm{T}$ : Postnatal ontogenesis of hippocampal CA1 area in rats. I. Development of dendritic arborisation in pyramidal neurons. Brain Res Bull 7, 113-120 (1981)

34 Li D, Field PM, Yoshioka N and Raisman G: Axons regenerate with correct specificity in horizontal slice culture of the postnatal rat entorhino-hippocampal system. Eur J Neurosci 6, 1026- 1037 (1994) 